\title{
Fingerprinting of phospholipid molecular species from human milk and infant formula using HILIC-ESI-IT-TOF-MS and discriminatory analysis by principal component analysis
}

\begin{abstract}
Phospholipid composition in the milk fat globule membrane (MFGM) fluctuates during the entire lactation period in order to suit the growing needs of newborn infants. The present study elucidated and relatively quantified phospholipid molecular species extracted from human milk (HM), mature human milk (MHM), and infant formulas (with or without MFGM supplementation) using hydrophilic liquid chromatography-electrospray ionization-ion traptime of flight-mass spectrometry (HILIC-ESI-IT-TOF-MS) system. Principal component analysis was used to clarify the differences between phospholipid composition in HM, MHM, and infant formulas. HM and MHM contained high concentrations of sphingomyeline (HM: $107.61 \mu \mathrm{g} / \mathrm{mL}$, MHM: $227.18 \mu \mathrm{g} / \mathrm{mL}$ ), phosphatidylcholine (HM: $59.96 \mu \mathrm{g} / \mathrm{mL}$, MHM: 50.77 $\mu \mathrm{g} / \mathrm{mL}$ ), and phosphatidylethanolamine (PE) (HM: $25.24 \mu \mathrm{g} / \mathrm{mL}, \mathrm{MHM}: 31.76 \mu \mathrm{g} / \mathrm{mL}$ ). Significant concentrations ( $<300 \mathrm{ng} / \mathrm{mL}$ ) of arachidonic, eicosapentanoic, and docosahexanoic acids were found to esterify to PE in HM and MHM. Meanwhile, all infant formulas were found to contain high concentrations of phosphatidic acids indicating the possibility of degradation of the fortified MFGM either during processing or storage of the infant formulas.
\end{abstract}

Keyword: Human milk; Infant formulas; Phospholipids; Milk fat globule membrane 
